\title{
Analisis Kelayakan Rencana Investasi Travel Baru Menggunakan Metode Hesitant Fuzzy Sets
}

\section{Feasibility Analysis of New Travel Investment Plans Using the Hesitant Fuzzy Sets Method}

\author{
Andreas Setijono ${ }^{1}$, Yurida Ekawati ${ }^{1 *}$ \\ ${ }^{1}$ Program Studi Teknik Industri, Universitas Ma Chung, Villa Puncak Tidar Blok N No. 1, Dau, Malang 65151, \\ Indonesia
}

Diterima: 6 Februari, 2019 / Disetujui: 3 Juli, 2019

\begin{abstract}
Transportation is a tool that supports the construction and economic development of a country. Because in this modern era, transportation provides easy access to the movement of goods and people from one place to another. This research was conducted at a company engaged in public transportation services. The main services provided are inter-city buses in the province, inter-city inter-provincial buses, tour buses and travel transportation. In 2018, the company has plans to add six travel vehicles and the capital owned is 500.000.000 Rupiah. While the remaining capital needed will be borrowed from Bank Antardaerah, so a business feasibility study is needed that can determine whether or not the investment plan is feasible. In addition, the Hesitant Fuzzy Sets method is used to model all forms of uncertainty that can cause losses. Hesitant Fuzzy Sets are an extension of the fuzzy set to handle inaccuracies where there are two or more sources of obscurity that appear simultaneously. Some basic methods used to determine the feasibility of investment plans are Payback Period (PP), Minimum Acceptable Rate of Return (MARR) and Internal Rate of Return (IRR). In addition, the Hesitant Fuzzy Sets method is used to model all forms of uncertainty that can cause losses. One example of such uncertainty is income uncertainty and expenditure uncertainty which are received by the company every year. The reason for using Hesitant Fuzzy Sets, because the method is an extension of the fuzzy set that can handle inaccuracies where there are two or more sources of obscurity that appear simultaneously.
\end{abstract}

Keywords: Transportation, Business feasibility study, Investment, Hesitant fuzzy sets

\begin{abstract}
ABSTRAK
Transportasi merupakan sarana yang menunjang perkembangan pembangunan dan perekonomian suatu negara. Sebab di era modern ini, transportasi memberikan kemudahan akses perpindahan barang maupun manusia dari suatu tempat ke tempat yang lain. Penelitian ini dilakukan pada salah satu perusahaan yang bergerak di pelayanan jasa transportasi umum. Pelayanan utama yang diberikan adalah bus antar kota dalam provinsi, bus antar kota antar provinsi, bus pariwisata dan transportasi travel. Pada tahun 2018, perusahaan memiliki rencana untuk menambah kendaraan travel sebanyak enam unit dan modal yang dimiliki sebesar Rp 500.000.000. Sedangkan sisa modal yang dibutuhkan akan dipinjam dari Bank Antardaerah, sehingga dibutuhkan studi kelayakan usaha yang dapat menentukan layak atau tidaknya rencana investasi tersebut. Beberapa metode dasar yang digunakan untuk menentukan kelayakan rencana investasi adalah Payback Period (PP), Minimum Acceptable Rate of Return (MARR) dan Internal Rate of Return (IRR). Selain itu, digunakanlah metode Hesitant Fuzzy Sets untuk memodelkan segala bentuk ketidakpastian yang dapat menyebabkan kerugian. Salah satu contoh ketidakpastian tersebut adalah ketidakpastian pendapatan dan ketidakpastian pengeluaran yang diterima oleh perusahaan setiap tahun. Alasan penggunaan Hesitant Fuzzy Sets, karena metode tersebut merupakan perpanjangan dari himpunan fuzzy yang dapat menangani ketidakakuratan dimana terdapat dua atau lebih sumber ketidakjelasan yang muncul secara bersamaan.
\end{abstract}

Kata Kunci: Transportasi, Studi kelayakan, Investasi, Hesitant fuzzy sets

*email: yurida.ekawati@gmail.com 


\section{PENDAHULUAN}

Transportasi merupakan sarana yang menunjang perkembangan pembangunan dan perekonomian suatu negara. Sebab di era modern ini, transportasi memberikan kemudahan akses perpindahan barang maupun manusia dari suatu tempat ke tempat yang lain. Selain itu, transpotasi juga sudah menjadi kebutuhan dasar bagi masyarakat. Sehingga pemerintah harus membuat kesinambungan antara ketersediaan pelayanan jasa transportasi dalam memenuhi kebutuhan aktivitas produksi, konsumsi dan distribusi. Perkembangan transportasi di Indonesia terbilang cukup cepat, hal ini dibuktikan dengan jumlah kendaraan yang terus bertambah setiap tahunnya. Pada tahun 2017, jumlah kendaraan bermotor di Indonesia sudah mencapai 138,56 juta unit (Badan Pusat Statistik, 2017). Jumlah kendaraan bermotor tersebut didominasi oleh kendaraan pribadi sebanyak 128,52 juta unit dan kendaraan umum sebanyak 10,04 juta unit. Hasil ini membuktikan bahwa pertumbuhan kendaraan pribadi dan kendaraan umum tidak seimbang sehingga menyebabkan masalah yang serius yaitu kemacetan. Maka dari itu, sebaiknya masyarakat mulai beralih kembali menggunakan transportasi umum untuk mengurangi dampak kemacetan.

Penelitian ini dilakukan pada salah satu perusahaan yang bergerak di pelayanan jasa transportasi umum. Pelayanan utama yang diberikan oleh perusahaan adalah bus antar kota dalam provinsi, bus antar kota antar provinsi dan bus pariwisata. Sedangkan untuk jasa transportasi travel, perusahaan baru merintis usaha tersebut sekitar empat tahun yang lalu sehingga armada yang dimiliki masih sangat sedikit. Jumlah travel yang dimiliki oleh perusahaan sebanyak 18 unit, oleh karena itu perusahaan berencana untuk menambah jumlah travel mereka. Perusahaan memiliki rencana untuk menambah armada travel mereka sebanyak enam unit dan akan dilaksanakan pada awal tahun 2018. Perusahaan memiliki modal awal sebesar Rp 500.000.000 untuk investasi enam unit travel ini, sedangkan sisanya mereka akan meminjam dari Bank Antardaerah. Oleh karena itu, perlu dilakukan perhitungan anggaran yang tepat mengenai rencana investasi yang akan dilaksanakan pada awal tahun 2018 ini.

Masalah yang telah teridentifikasi adalah perusahaan memiliki rencana untuk menambah unit travel namun belum dilakukan uji kelayakan usaha terkait hal tersebut. Selain itu, rencana investasi ini membutuhkan modal yang cukup besar sehingga perlu dilakukan perhitungan mengenai risiko yang mungkin timbul. Beberapa macam risiko tersebut antara lain kenaikan harga unit travel baru, umur proyek yang tidak sesuai dengan rencana, dan pendapatan yang tidak sesuai dengan perkiraan.

Tujuan utama dari penelitian ini tidak hanya melakukan analisis kelayakan usaha yang ada pada umumnya seperti menghitung aspek pemasaran, aspek teknis, aspek hukum dan aspek finansial, tetapi juga memperhitungkan risiko dan faktor-faktor yang dapat menyebabkan kerugian. Oleh karena itu, metode hesitant fuzzy sets digunakan untuk memodelkan segala bentuk ketidakpastian yang dapat menyebabkan kerugian. Ketidakpastian yang dapat terjadi yaitu ketidakpastian harga beli unit travel baru, ketidakpastian tingkat suku bunga pinjaman bank, ketidakpastian income yang didapat, ketidakpastian umur investasi, dan lainlain. Sehingga, dengan penggunaan metode hesitant fuzzy sets ini, perusahaan dapat meminimalkan kerugian apabila investasi ini dijalankan dan membantu dalam pengambilan keputusan. Hal ini sangat dibutuhkan karena sebagian besar modal yang digunakan untuk investasi tersebut adalah hutang dari Bank Antardaerah dan harus terlunasi selama 5 tahun.

\section{TINJAUAN PUSTAKA}

\subsection{Studi Kelayakan}

Studi kelayakan merupakan suatu kegiatan yang dilakukan dalam rangka menentukan layak atau tidaknya suatu usaha yang akan dijalankan dengan cara mempelajari secara mendalam kegiatan atau usaha bisnis tersebut (Kasmir dan Jakfar, 2007). Selain itu, studi kelayakan sangat diperlukan agar apabila usaha dijalankan tidak menimbulkan kerugian biaya, tenaga atau pikiran secara percuma, serta tidak menyebabkan masalah yang tidak perlu dimasa yang akan datang.

\subsection{Investasi}

Investasi adalah penanaman dana ke dalam aktiva baik aktiva riil maupun aktiva nonriil yang dilakukan oleh suatu perusahaan guna memperoleh pendapatan yang sesuai dengan target perusahaan di masa akan dating (Harjito dan Martono, 2012). Secara umum investasi terbagi menjadi dua macam yaitu investasi 
aktiva nyata dan investasi aktiva finansial. Investasi aktiva nyata merupakan tindakan investasi dalam bentuk fisik yang dapat dilihat secara nyata. Misalnya seperti membangun rumah, pabrik atau bisa juga dengan membeli mesin, dan lain-lain. Sedangkan Investasi aktiva finansial merupakan tindakan investasi dalam bentuk surat-surat berharga. Misalnya seperti deposito, obligasi, saham dan lain-lain.

\subsection{Biaya Modal}

Definisi biaya modal adalah biaya riil yang dikeluarkan oleh perusahaan untuk membiayai suatu investasi atau kegiatan operasional perusahaan, yang berasal dari berbagai sumber seperti hutang, saham preferen, saham biasa, maupun laba ditahan (Harjito dan Martono, 2012). Penentuan besarnya biaya modal ini dimaksudkan untuk mengetahui berapa besarnya biaya riil yang harus dikeluarkan perusahaan untuk memperoleh dana yang diperlukan.

\subsection{Nilai Waktu Uang}

Nilai waktu uang merupakan perbandingan antara nilai uang pada waktu tertentu dengan nilai uang pada waktu yang lain. Sebagai contoh, nilai mata uang Rp 50.000 pada saat ini tentu lebih berharga daripada nilai sebesar uang tersebut pada 10 atau 15 tahun mendatang. Hal ini disebabkan oleh adanya inflasi atau tingkat suku bunga. Perubahan nilai uang di masa sekarang (present value) menjadi nilai uang di masa mendatang (future value) disebut dengan pemajemukan (compounding) (Brigham dan Houston, 2019).

\subsection{Depresiasi}

Depresiasi adalah alokasi biaya dalam setiap periode akuntansi yang secara sistematis didapat dari sebagian harga perolehan aktiva tetap (Baridwan, 2014). Penyusutan atau depresiasi merupakan proses pengalokasian harga perolehan, bukan proses penilaian aktiva tetap. Depresiasi merupakan komponen penting dalam analisis ekonomi teknik karena dapat dipergunakan untuk mengetahui nilai suatu aset sesuai dengan waktu penggunaannya. Selain itu, depresiasi dapat dipergunakan untuk pengurangan pengenaan pajak dengan cara menghitung aset yang diinvestasikan termasuk sebagai biaya produksi atau biaya operasi. Perhitungan besarnya penyusutan harta tetap berwujud dibagi menjadi dua golongan, yaitu harta berwujud yang bukan berupa bangunan dan harta berwujud yang berupa bangunan (Direktorat Jenderal Pajak, 2018). Tabel 1 menggelompokkan depresiasi pajak berdasarkan wujud harta, metode dan tarif penyusutannya.

Tabel 1. Informasi Depresiasi Pajak (Direktorat Jenderal Pajak, 2018)

\begin{tabular}{llll} 
Kelompok & Masa & \multicolumn{2}{l}{ Tarif Depresiasi } \\
\cline { 3 - 4 } $\begin{array}{l}\text { Harta } \\
\text { Berwujud }\end{array}$ & Manfaat & $\begin{array}{l}\text { Garis } \\
\text { Lurus }\end{array}$ & $\begin{array}{l}\text { Saldo } \\
\text { Menurun }\end{array}$ \\
\hline $\begin{array}{l}\text { I. Bukan } \\
\text { Bangunan }\end{array}$ & & & \\
$\begin{array}{l}\text { Kelompok 1 } \\
\text { Kelompok 2 }\end{array}$ & 8 tahun & $25 \%$ & $50 \%$ \\
$\begin{array}{l}\text { Kelompok 3 } \\
\text { Kelompok 4 }\end{array}$ & 16 tahun & $12,5 \%$ & $25 \%$ \\
$\begin{array}{l}\text { Kelohun } \\
\text { II. Bangunan }\end{array}$ & $5 \%$ & $12,5 \%$ \\
$\begin{array}{l}\text { Permanen } \\
\text { Tidak }\end{array}$ & 20 tahun & $5 \%$ & - \\
Permanen & 10 tahun & $10 \%$ & - \\
\hline
\end{tabular}

\subsection{Cash Flow}

Aliran kas atau yang biasa dikenal dengan cash flow merupakan rincian aliran kas baik pendapatan maupun pengeluaran yang ada pada perusahaan dalam suatu periode tertentu. Cash flow memberi gambaran berupa uang yang masuk (cash in) ataupun yang keluar (cash out) ke dalam kas perusahaan beserta dengan jenisjenis pemasukan dan pengeluaran yang diterima oleh perusahaan. Cash flow juga dapat menggambarkan tentang seberapa banyak uang yang keluar (cash out) dan jenis-jenis biaya yang dikeluarkan oleh perusahaan tersebut (Kasmir dan Jakfar, 2007). Berikut merupakan contoh gambar dari cash flow diagram:

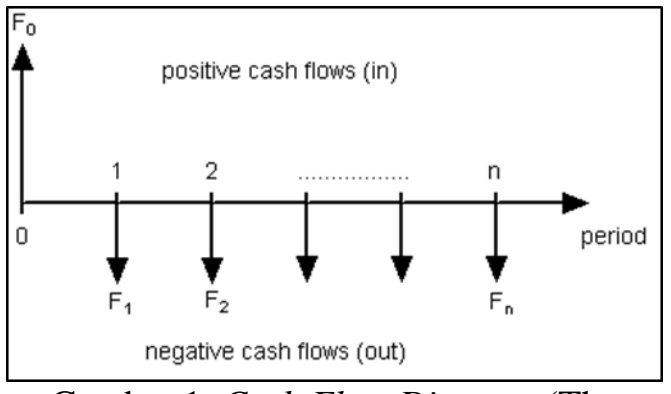

Gambar 1. Cash Flow Diagram (The Engineering Toolbox, 2008)

\subsection{Payback Period}

Payback period merupakan suatu metode yang menghitung berapa lama investasi akan kembali atau periode yang diperlukan untuk menutup kembali pengeluaran investasi (initial 
investment) dengan menggunakan aliran kas (Situmorang dan Dilham, 2007). Sehingga payback period juga bisa disebut sebagai rasio antara initial investment dengan cash flow, yang hasilnya merupakan satuan waktu. Suatu usulan investasi akan disetujui apabila memiliki payback period yang lebih cepat atau lebih pendek dari payback period yang disyaratkan oleh perusahaan. Persamaan (1) merupakan rumus untuk menghitung payback period apabila arus kas dari suatu rencana investasi/proyek sama jumlahnya setiap tahun:

$$
P P=\frac{I}{C F}(1 \text { tahun })
$$

dimana:

$$
\begin{array}{ll}
P P & =\text { Payback Period } \\
I & =\text { Initial Investment } \\
C F & =\text { Cash Flow }
\end{array}
$$

\subsection{Fuzzy}

Beberapa kurun abad ini teori probabilitas memegang peranan penting untuk menjelaskan pengertian tentang ketidakpastian. Pada tahun 1965, Prof. Lotfi A. Zadeh dari Universitas California di Barkeley memperkenalkan konsep tentang himpunan fuzzy (fuzzy set = himpunan kabur) yang secara tidak langsung menyatakan bahwa selain pendekatan probabilitas, ketidakpastian dapat didekati dengan metode lain, dalam hal ini konsep himpunan fuzzy.

Teori himpunan fuzzy merupakan kerangka matematis yang dapat digunakan untuk merepresentasikan ketidakpastian, ketidakjelasan, ketidaktepatan, kekurang informasian dan kebenaran parsial (Tettamanzi dan Tomassini, 2001). Pada dasarnya himpunan fuzzy merupakan perluasan dari himpunan klasik (crisp), pada himpunan klasik $A$ suatu elemen akan memiliki dua kemungkinan keanggotaan yaitu anggota $A$ dinotasikan dengan $\mu A(x)$. Pada himpunan klasik ada dua keanggotaan yaitu $\{\mu A(x)=1\}$ apabila $x$ merupakan anggota $A$ dan $\{\mu A(x)=0\}$ apabila $x$ bukan anggota $A$. Berbeda dengan himpunan klasik, himpunan fuzzy memperlakukan elemen dalam derajat keanggotaan. Sehingga dalam konsep himpunan fuzzy dan dalam dunia nyata "kedua pernyataan benar" dan mungkin sebagai jawaban.

Logika fuzzy dewasa ini banyak digunakan untuk berbagai macam keperluan, seperti sistem pendukung keputusan, penentuan produksi barang dan pengenalan pola. Logika fuzzy terdiri dari tiga tahap utama yaitu fuzzifikasi, inferensi, dan defuzzifikasi. Fuzzifikasi adalah proses perubahan variabel numerik menjadi variabel linguistik. Fungsi fuzzifikasi digunakan untuk mengubah nilai tegas, misal $\mathrm{A} \in \mathrm{B}$, ke suatu himpunan fuzzy $\mathrm{C}$ dengan nilai keanggotaan A. Fuzzifikasi diharapkan dapat membantu menyederhanakan komputasi yang harus dilakukan oleh sistem tersebut dalam proses inferensinya. inferensi adalah proses merumuskan pemetaan dari masukan yang diberikan ke sebuah output dengan menggunakan logika fuzzy. Pemetaan tersebut membutuhkan proses operasi yang kemudian dapat memberikan dasar dari mana keputusan dapat dibuat, atau pola dilihat. Defuzzifikasi digunakan untuk menerjemahkan himpunan nilai keluaran kedalam nilai yang tegas. Ada beberapa metode defuzzifikasi dalam pemodelan sistem fuzzy.

\subsection{Hesitant Fuzzy Sets}

Hesitant Fuzzy Sets merupakan perpanjangan dari himpunan fuzzy untuk menangani ketidakakuratan dimana terdapat dua atau lebih sumber ketidakjelasan yang muncul secara bersamaan (Kahraman, Onar dan Öztayşi, 2015). Berbeda dengan dengan himpunan fuzzy lainnya, Hesitant Fuzzy Sets mendefinisikan nilai keanggotaan elemennya berdasarkan serangkaian nilai yang mungkin terjadi. Hesitant Fuzzy Sets juga dapat diartikan sebagai bentuk fungsi yang mengembalikan satu set nilai keanggotaan untuk setiap elemen dalam domain. Tahap awal dari metode ini yaitu fuzzifikasi. Fuzzifikasi yang dimaksud dalam hal ini adalah memodelkan ketidakpastian yang berasal dari keraguan yang mungkin timbul dalam penugasan derajat keanggotaan elemen ke dalam himpunan fuzzy. Tahap kedua yaitu inferensi. Proses inferensi dalam penelitian ini akan menggunakan proses operasi complement/NOT. Persamaan (2) adalah rumus yang digunakan dalam operasi complement:

$$
\begin{aligned}
& \mu A=\left[1-(1-L j)^{w i},(1-M j)^{w j},(1\right. \\
& \left.-U j)^{w j}\right]
\end{aligned}
$$

dimana:

$L, M$ dan $U$ :nilai pembobotan secara acak yang didapat pada proses fuzzifikasi. 
Wj

:bobot nilai yang didapat dari para ahli atau yang biasa disebut experts weights.

Tahap ketiga yaitu menentukan nilai defuzzifikasi dari masing-masing parameter. Defuzzifikasi merupakan proses pengubahan besaran fuzzy ke dalam bentuk bilangan real. Persamaan (3) menjelaskan rumus yang digunakan untuk menghitung nilai defuzzifikasi.

$$
D e f=\frac{l+2 m+u}{4}
$$

dimana:

$1, \mathrm{~m}$ dan $\mathrm{u} \quad$ :nilai yang didapat setelah melalui proses inferensi

Def :nilai deffuzifikasi yang menggubah nilai input dari besaran fuzzy menjadi bentuk bilangan riil.

\subsection{Present Worth Analysis}

Hesitant Fuzzy Sets dapat digunakan untuk mengekspresikan parameter investasi (Kahraman, Onar dan Öztayşi, 2015). Parameter yang ditangani adalah First Cost (FC), Uniform Annual Cost (UAC), Uniform Annual Benefit (UAB), umur proyek $(\mathrm{N})$, tingkat suku bunga $(i)$, dan Salvage Value (SV). Parameter ini ditunjukkan pada persamaan (4).

$$
\begin{aligned}
P W=-F C- & U A C\left(\frac{P}{A}, i, n\right) \\
& +U A B\left(\frac{P}{A}, i, n\right) \\
+ & S V\left(\frac{P}{A}, i, n\right)
\end{aligned}
$$

Penggunaan present worth ini didasarkan pada konsep ekuivalensi di mana semua arus kas masuk dan arus kas keluar diperhitungkan dalam titik waktu sekarang pada suatu tingkat pengembalian minimum yang diinginkan. Apabila diperoleh nilai $\mathrm{PW} \geq 0$, maka proyek tersebut layak diterima. Sementara untuk situasi dimana terdapat lebih dari satu alternatif, maka alternatif dengan nilai PW terbesar merupakan alternatif yang paling menarik untuk dipilih. Pada situasi dimana alternatif yang ada bersifat independent, dipilih semua alternatif yang memiliki nilai $\mathrm{PW} \geq 0$. Namun, apabila diperoleh nilai $\mathrm{PW} \leq 0$, maka proyek tersebut tidak layak untuk diterima.

\section{METODE PENELITIAN}

Berikut merupakan rincian mengenai langkah-langkah dari sistematika metodologi penelitian:

1. Pengamatan awal dan identifikasi masalah Pengamatan awal dilakukan untuk identifikasi masalah yang dialami oleh perusahaan yaitu terkait dengan rencana investasi. Pengamatan awal dilakukan dengan melakukan studi lapangan dan wawancara dengan pihak perusahaan. Studi lapangan ke perusahaan dilakukan untuk mengetahui gambaran umum tentang proses keuangan perusahaan, sedangkan wawancara dilakukan untuk mengetahui lebih detail mengenai proses penambahan unit travel. Melalui pengamatan awal ini, permasalahan-permasalahan yang terjadi pada perusahaan dapat teridentifikasi.

2. Perumusan Masalah

Inti dari perumusan masalah ini adalah menentukan masalah utama yang ditemukan pada perusahaan yaitu terkait dengan kelayakan rencana investasi. Kemudian meringkas masalah tersebut dan memberikan solusi yang terbaik. Oleh karena itu, perusahaan dapat mengetahui bagaimana hasil analisis kelayakan usaha terkait rencana penambahan enam unit travel baru tersebut dengan memperhitungkan aspek ketidakpastian.

3. Penentuan Tujuan dan Batasan Penelitian Tujuan utama dari penelitian ini tidak hanya melakukan analisis kelayakan usaha tetapi juga memperhitungkan risiko dan faktorfaktor yang dapat menyebabkan kerugian. Sedangkan batasan penelitian dilakukan untuk membatasi bagian-bagian yang diteliti dalam penelitian ini. Batasan penelitian juga diperlukan agar hasil yang dicapai dalam penelitian ini sesuai dengan yang diinginkan. Penjelasan yang terdapat pada batasan masalah juga ditentukan mengenai metode yang digunakan pada saat penelitian. Adapun batasan masalah yang ada dalam penelitian ini yaitu perhitungan biaya modal hanya dilakukan khusus untuk penambahan unit travel baru. Selain itu, metode Hesitant Fuzzy Sets hanya digunakan untuk menghitung aspek finansial.

4. Studi Literatur

Studi literatur dilakukan untuk memahami beberapa hal yang berkaitan dengan metode maupun teori yang digunakan dalam 
penelitian ini. Tujuan dari studi literatur adalah untuk mempelajari dan mendalami ilmu yang berkaitan dengan penelitian yang dilakukan. Pada penelitian ini, studi literatur yang akan dipelajari adalah mengenai topik yang berkaitan dengan studi kelayakan usaha, penerapan logika fuzzy, dan metode Hesitant Fuzzy Sets yang digunakan untuk menghitung nilai dari present worth.

5. Jenis Data

Pengumpulan data adalah teknik atau cara yang dilakukan untuk mengumpulkan data. Berikut merupakan langkah-langkah yang ada dalam proses pengumpulan data:

a. Data Primer

Data primer merupakan data yang didapat secara langsung dari hasil pengamatan dan wawancara langsung kepada pihak perusahaan.

b. Data Sekunder

Data sekunder adalah data yang tidak didapatkan secara langsung melainkan bersumber dari data yang sudah ada dengan bantuan pihak perusahaan. Data sekunder yang diperoleh dari penelitian tugas akhir ini adalah laporan keuangan, laporan laba rugi, dan beberapa laporan penunjang lainnya.

6. Studi Kelayakan

Studi kelayakan dilakukan untuk mengetahui layak atau tidak rencana investasi yang akan dijalankan. Studi kelayakan ini dilakukan berdasarkan kondisi aktual dari perusahaan. Pada penelitian kali ini, terdapat empat aspek yang akan dijadikan sebagai acuan dari studi kelayakan. Keempat aspek kelayakan tersebut adalah aspek pemasaran, aspek teknis, aspek hukum dan aspek finansial.

7. Simpulan

Tahap terakhir yang dilakukan yaitu memberikan kesimpulan dan saran dari penelitian yang dilakukan. Simpulan yang diberikan dibuat berdasarkan hasil analisis yaitu besaran keuntungan yang diterima selama proyek dijalankan. Selain itu diberikan saran kepada perusahaan ataupun bagi peneliti lain terkait dengan studi kelayakan usaha.

\section{HASIL DAN PEMBAHASAN}

\subsection{Biaya Operasional}

Berdasarkan hasil wawancara dengan pihak operasional dan hasil observasi, diketahui bahwa terdapat beberapa macam biaya yang digunakan untuk proses operasional di bagian travel. Tabel 2 menjelaskan rincian biaya yang digunakan.

\subsection{Pendapatan}

Perusahaan berasumsi bahwa pendapatan per hari $\mathrm{Rp} 400.000$ maka dalam sebulan mampu menghasilkan sebesar Rp 12.000.000. Kemudian perkiraan pendapatan untuk enam unit kendaraan travel dalam setahun sebesar Rp 864.000.000. Pendapatan tersebut merupakan hasil laba bersih ketika kendaraan travel beroperasi. Namun nilai tersebut masih belum dipotong dengan biaya tenaga kerja dan biaya operasional.

\subsection{Depresiasi}

Harga satu unit travel sebesar $\mathrm{Rp}$ 350.000.000 dan keseluruhan harga perolehan untuk enam unit travel sebesar Rp 2.100.000.000. Berikut rincian tabel penyusutan untuk rencana investasi yang dilakukan perusahaan.

\subsection{Taxable Gain / Taxable Loss}

Perusahaan berpendapat bahwa pada akhir tahun 2022 seluruh aset investasi masih memiliki nilai sebesar Rp 1.200.000.000 dengan asumsi satu unit travel laku sebesar Rp 200.000.000. Oleh karena itu, perusahaan akan menerima taxable gain apabila salvage value > book value atau taxable loss apabila salvage value < book value. Berdasarkan hasil sebelumnya didapatkan book value sebesar $\mathrm{Rp}$ 498.339.843, maka dapat disimpulkan bahwa perusahaan menerima taxable gain karena salvage value lebih besar dari book value. Berikut perhitungan nilai dari taxable gain:

Taxable Gain = Salvage Value - Book Value 498.339 .843

$$
=\mathrm{Rp} 1.200 .000 .000-\mathrm{Rp}
$$

$$
=\operatorname{Rp} 701.660 .157
$$

Nilai dari taxable gain tersebut akan digunakan dalam perhitungan yang ada pada bagian cash flow. Kemudian diperlakukan sebagai pendapatan dan dimasukkan dalam perhitungan pajak pada tahun 2023 karena hasil penjualan aset pada akhir tahun 2022 memberikan keuntungan bagi perusahaan. 
Tabel 2. Rincian Biaya Operasional

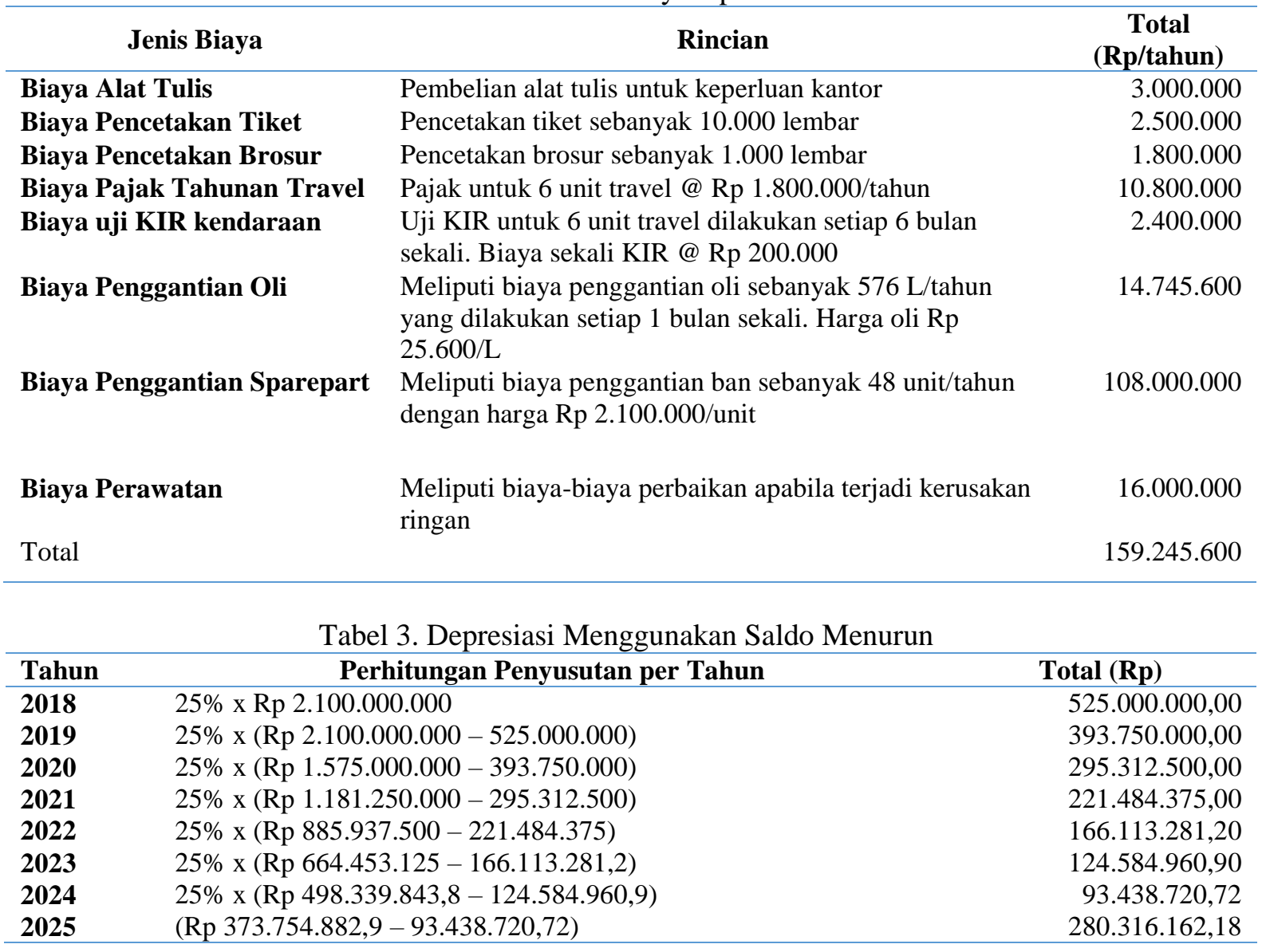

Tabel 4. Initial Investment

Total biaya modal

Estimasi Harga Perolehan Travel (Rp)

Pajak dan fee (10\%) (Rp)

Modal awal perusahaan (Rp)

Biaya Modal (Rp)

$\begin{array}{rr}2.100 .000 .000 & \\ 210.000 .000 & \underline{(500.000 .000)} \\ & \\ & 1.810 .000 .000\end{array}$

\subsection{Initial Investment}

Perhitungan initial investment ini akan digunakan untuk menentukan besarnya dana yang harus dipinjam dari bank Antardaerah. Tabel 4 menunjukkan estimasi perhitungan initial investment.

\subsection{Cash Flow}

Berdasarkan data yang didapatkan pada awal tahun 2018, suku bunga pinjaman dari bank Antardaerah sebesar 10,86\% dengan biaya provisi sekitar 1,2\%. Maka estimasi cicilan pinjaman yang harus dibayar setiap bulan sebesar Rp 39.698.261. Setelah mengetahui seluruh biaya, pendatapatan, depresiasi dan lain-lain. Maka langkah selanjutnya adalah menggambarkannya ke dalam cash flow diagram. Gambar 2 merupakan cash flow diagram selama lima periode.

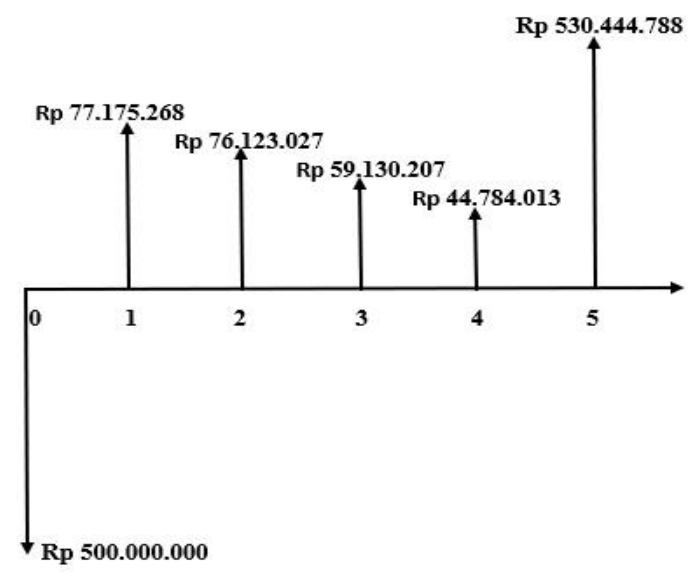

Gambar 2. Cash Flow Diagram Rencana Investasi 


\subsection{Payback Period}

$$
\begin{aligned}
\mathrm{PP} & =\frac{\text { Initial Investment }}{\text { Cash Flow }} \times 1 \text { tahun } \\
& =\frac{\mathrm{Rp} 2.310 .000 .000}{(864.000 .000-159.245 .600-151.200 .000)} \times 1 \\
& =4,173 \text { tahun } \approx 50 \text { bulan }
\end{aligned}
$$

\subsection{Minimum Acceptable Rate of Return (MARR)}

Modal yang berasal dari hutang sebesar 78,35\% dengan tingkat suku bunga pinjaman 10,86\% per tahun. Sedangkan modal dari perusahaan sebesar $21,65 \%$ dan tingkat pengembalian yang diinginkan setidaknya harus sama dengan tingkat suku bunga deposito yang tertinggi yaitu 6,4\%. Apabila perusahaan tidak memperhitungkan risiko investasi, maka nilai MARR yang didapat sebesar 9,89\%. Apabila perusahaan menambahkan pertimbangan risiko investasi sebesar 5\%, maka nilai MARR yang didapat sebesar 14,89\%. Berikut perhitungannya:

$$
\begin{aligned}
\text { MARR }= & \operatorname{Rd} \times \mathrm{Id}+(1-\mathrm{rd}) \mathrm{ie}+5 \% \\
= & (0,7835) \times(0,1086)+(1-0,7835) \times \\
& (0,064)+5 \% \\
= & 14,89 \%
\end{aligned}
$$

\subsection{Hesitant Fuzzy Sets}

Hesitant Fuzzy Sets dikenal sebagai ekstensi baru dari himpunan fuzzy yang muncul karena adanya beberapa nilai yang dapat menimbulkan keraguan dalam pengambilan keputusan. Kegunaan dari Hesitant Fuzzy Sets yaitu untuk menangani ketidakakuratan dimana terjadi dua atau lebih sumber ketidakjelasan yang muncul secara bersamaan. Sehingga metode ini akan mempresentasikan segala sumber ketidakjelasan dan ketidakakuratan yang mungkin dapat menimbulkan risiko kerugian.

\begin{tabular}{|c|c|c|c|c|}
\hline \multirow{3}{*}{ Parameter } & \multirow{3}{*}{ Possible value } & \multicolumn{3}{|c|}{ Expert's weights } \\
\hline & & E1 & E2 & E3 \\
\hline & & 0,15 & 0,6 & 0,25 \\
\hline \multirow[t]{3}{*}{$F C$} & Rp 470.000.000 & $(0.9,0.7,0.1)$ & $(0.2,0.5,0.5)$ & $(0.3,0.1,0.4)$ \\
\hline & Rp 500.000.000 & $(0.4,0.2,0.6)$ & $(0.5,0.3,0.6)$ & $(0.4,0.1,0.9)$ \\
\hline & Rp 540.000.000 & $(0.8,0.1,0.9)$ & $(0.7,0.5,0.9)$ & $(0.5,0.4,0.5)$ \\
\hline \multirow[t]{3}{*}{$\boldsymbol{U} \boldsymbol{A} \boldsymbol{C}$} & Rp 766.824.732 & $(0.4,0.6,0.8)$ & $(0.3,0.2,0.5)$ & $(0.8,0.3,0.4)$ \\
\hline & Rp 786.824.732 & $(0.9,0.5,0.7)$ & $(0.8,0.9,0.3)$ & $(0.4,0.1,0.3)$ \\
\hline & Rp 847.779.810 & $(0.5,0.2,0.8)$ & $(0.4,0.8,0.5)$ & $(0.8,0.2,0.9)$ \\
\hline \multirow[t]{3}{*}{$U A B$} & $\operatorname{Rp} 705.600 .000$ & $(0.1,0.3,0.6)$ & $(0.1,0.8,0.3)$ & $(0.7,0.6,0.2)$ \\
\hline & Rp 864.000.000 & $(0.4,0.5,0.4)$ & $(0.7,0.2,0.8)$ & $(0.2,0.5,0.6)$ \\
\hline & Rp 927.360 .000 & $(0.5,0.9,0.7)$ & $(0.6,0.4,0.3)$ & $(0.6,0.5,0.2)$ \\
\hline \multirow[t]{3}{*}{$S V$} & Rp 1.050.000.000 & $(0.1,0.7,0.9)$ & $(0.2,0.7,0.6)$ & $(0.7,0.5,0.9)$ \\
\hline & $\mathrm{Rp} 1.200 .000 .000$ & $(0.8,0.3,0.2)$ & $(0.2,0.7,0.5)$ & $(0.2,0.1,0.9)$ \\
\hline & Rp 1.320.000.000 & $(0.6,0.2,0.2)$ & $(0.4,0.6,0.6)$ & $(0.2,0.8,0.6)$ \\
\hline \multirow[t]{3}{*}{$i$} & $6,4 \%$ & $(0.5,0.4,0.9)$ & $(0.2,0.3,0.9)$ & $(0.4,0.5,0.5)$ \\
\hline & $9,89 \%$ & $(0.2,0.2,0.8)$ & $(0.3,0.7,0.5)$ & $(0.9,0.6,0.2)$ \\
\hline & $14,89 \%$ & $(0.6,0.1,0.1)$ & $(0.3,0.5,0.4)$ & $(0.2,0.8,0.5)$ \\
\hline \multirow[t]{3}{*}{$N$} & 3 tahun & $(0.4,0.7,0.2)$ & $(0.9,0.4,0,4)$ & $(0.8,0.8,0.2)$ \\
\hline & 5 tahun & $(0.2,0.6,0.4)$ & $(0.9,0.3,0.4)$ & $(0.2,0.5,0.2)$ \\
\hline & 8 tahun & $(0.5,0.2,0.7)$ & $(0.7,0.6,0.5)$ & $(0.3,0.6,0.5)$ \\
\hline
\end{tabular}
Beberapa parameter yang ditangani adalah First Cost, Uniform Annual Cost, Uniform Annual Benefit, umur investasi $(N)$, tingkat suku bunga (i) dan salvage value Annual. Tabel 5 menjelaskan proses fuzzifikasi.

Tabel 5. Fuzzifikasi 


\begin{tabular}{|c|c|c|c|c|}
\hline Parameter & Possible value & Aggregation & Defuzifikasi & Average \\
\hline \multirow[t]{3}{*}{$F C$} & Rp 470.000.000 & $(0.434,0.464,0.428)$ & 0,447 & \\
\hline & Rp 500.000.000 & $(0.462,0.240,0.717)$ & 0,415 & Rp 507.176.148 \\
\hline & Rp 540.000.000 & $(0.679,0.428,0.850)$ & 0,597 & \\
\hline \multirow[t]{3}{*}{$U A C$} & Rp 766.824 .732 & $(0.499,0.303,0,544)$ & 0,412 & \\
\hline & $\operatorname{Rp} 786.824 .732$ & $(0.763,0.780,0.384)$ & 0,676 & Rp 804.682.049 \\
\hline & Rp 847.779.810 & $(0.556,0.652,0.709)$ & 0,642 & \\
\hline \multirow[t]{3}{*}{$U A B$} & Rp 705.600.000 & $(0.316,0.713,0.335)$ & 0,519 & \\
\hline & Rp 864.000.000 & $(0.575,0.337,0.720)$ & 0,492 & Rp 831.698.417 \\
\hline & Rp 927.360 .000 & $(0.586,0.562,0.363)$ & 0,518 & \\
\hline \multirow[t]{3}{*}{$S V$} & Rp 1.050.000.000 & $(0.363,0.659,0.770)$ & 0,613 & \\
\hline & Rp 1.200.000.000 & $(0.350,0.552,0.641)$ & 0,524 & Rp 1.184.697.867 \\
\hline & Rp 1.320.000.000 & $(0.393,0.627,0.556)$ & 0,551 & \\
\hline \multirow[t]{3}{*}{$i$} & $4,4 \%$ & $(0.306,0.371,0.850)$ & 0,475 & \\
\hline & $5,8 \%$ & $(0.561,0.627,0.510)$ & 0,581 & $10,3 \%$ \\
\hline & $6,4 \%$ & $(0.335,0.566,0.391)$ & 0,464 & \\
\hline \multirow[t]{3}{*}{$N$} & 3 tahun & $(0.844,0.589,0.327)$ & 0,587 & \\
\hline & 5 tahun & $(0.770,0.408,0.355)$ & 0,486 & 5,8 tahun \\
\hline & 8 tahun & $(0.600,0.556,0.537)$ & 0,537 & \\
\hline
\end{tabular}

$$
\begin{aligned}
& \frac{0,434+2 \times 0,464+0,428}{4}=0,447 \\
& \frac{0,462+2 \times 0,240+0,717}{4}=0,415 \\
& \frac{0,679+2 \times 0,428+0,850}{4}=0,597
\end{aligned}
$$

\subsection{Penilaian Kelayakan Rencana \\ Investasi}

Penggunaan present worth ini didasarkan pada konsep ekuivalensi di mana semua arus kas masuk dan arus kas keluar diperhitungkan dalam titik waktu sekarang dengan suatu tingkat pengembalian minimum yang diinginkan.

$$
\begin{aligned}
& \mathrm{PW}^{\prime}=-\mathrm{FC}+\mathrm{UAB}(P / A, i, n)-\mathrm{UAC} \\
& (P / A, i, n)+\mathrm{SV} \quad(P / F, i, n) \\
& =-\mathrm{FC}+\left\{(\mathrm{UAB}-\mathrm{UAC}) \times \frac{(1+i)^{n}-1}{i(1+i)^{n}}\right\}+ \\
& \left\{\mathrm{SV} \times \frac{1}{(1+i)^{n}}\right\} \\
& =\quad-\quad 507.176 .148 \\
& \{(831.698 .417-804.682 .049) \\
& \begin{array}{l}
\left.\left.\frac{(1+5,54 \%)^{5,8}-1}{5,54 \%(1+5,54 \%)^{5,8}}\right)\right\}+\{1.184 .697 .867 \times \\
\left.\frac{1}{(1+5,54 \%)^{5,8}}\right\} \\
-507.176 .148+997.503 .945 \\
\operatorname{Rp} 277.494 .127
\end{array}
\end{aligned}
$$

Berdasarkan hasil sebelumnya diketahui bahwa nilai present worth yang didapat dari metode fuzzy sebesar Rp 277.494.127. Sehingga dapat disimpulkan bahwa investasi yang akan dijalankan layak untuk diterima karena nilai PW
$>0$. Besarnya keuntungan dari rencana investasi tersebut dapat dihitung menggunakan rumus IRR (Internal Rate of Return). IRR dapat dicari dengan cara membandingkan nilai $\mathrm{PW}$ yang bernilai positif dengan PW bernilai negatif. Karena PW yang bernilai positif sudah ditemukan maka langkah selanjutnya menentukan nilai PW bernilai negatif terlebih dahulu kemudian menghitung nilai IRR dengan bantuan perhitungan interpolasi. Berikut perhitungan PW bernilai negatif dan IRR untuk menghitung persentase tingkat pengembalian dari rencana investasi:

$$
\begin{aligned}
& \mathrm{PW}==-\mathrm{FC}+\mathrm{UAB}(P / A, i, n)-\mathrm{UAC} \\
& \begin{aligned}
&(P / A, i, n)+\mathrm{SV}(P / F, i, n) \\
&=-\mathrm{FC}+\left\{(\mathrm{UAB}-\mathrm{UAC}) \times \frac{(1+i)^{n}-1}{i(1+i)^{n}}\right\}+ \\
&\{\mathrm{SV} \quad\left.\times \frac{1}{(1+i)^{n}}\right\} \\
&=-
\end{aligned} \\
& +\{(831.698 .417-804.682 .049) \times \\
& \left.\frac{(1+20 \%)^{5,8}-1}{20 \%(1+20 \%)^{5,8}}\right\}+\{1.184 .697 .867 \quad \times \\
& \left.\quad \frac{1}{(1+20 \%)^{5,8}}\right\} \\
& =-507.176 .148+499.650 .410 \\
& =-\operatorname{Rp~} 7.525 .738
\end{aligned}
$$

$$
\begin{aligned}
\mathrm{IRR}= & 10,3 \%+\frac{\mathrm{Rp} 277.494 .127}{\operatorname{Rp} 784.670 .275-\operatorname{Rp} 499.650 .410)} \\
& \times(20 \%-10,3 \%)\} \\
= & 10,3 \%+(0,9736 \times 9,7 \%) \\
= & 19,74 \%
\end{aligned}
$$


Nilai IRR tersebut menunjukkan bahwa persentase tingkat pengembalian dari rencana investasi sekitar 19,74\%. Apabila dibandingkan dengan nilai MARR perusahaan yaitu sekitar $14,89 \%$ per tahun, maka rencana investasi tersebut dianggap jauh lebih menguntungkan. Berdasarkan penjelasan tersebut, maka rencana investasi yang akan dijalankan dapat dinyatakan layak apabila dinilai dari aspek finansial.

\section{SIMPULAN}

Perhitungan menggunakan metode payback period menunjukkan bahwa seluruh modal investasi dapat terlunasi dalam waktu 50 bulan. Berdasarkan hasil analisis menggunakan metode Hesitant Fuzzy Sets didapatkan hasil present worth sebesar Rp 277.494.127. Nilai tersebut diperoleh dengan memperkirakan segala risiko yang dapat terjadi selama investasi dilaksanakan. Perkiraan tingkat pengembalian investasi atau IRR dari rencana investasi adalah sebesar $19,74 \%$.

Penelitian lebih lanjut dapat membahas terkait dengan studi kelayakan usaha adalah penambahan metode fuzzy lain yang dapat digunakan dalam analisis studi kelayakan usaha. Salah satu metode fuzzy tersebut adalah Fuzzy $A H P$ yang dapat dilakukan untuk menentukan lokasi usaha dalam aspek teknis. Kemudian terdapat beberapa metode fuzzy yang lain seperti Fuzzy Mamdani, Fuzzy Tsukamoto dan Fuzzy Sugeno.

\section{DAFTAR PUSTAKA}

Badan Pusat Statistik (2017) Perkembangan Jumlah Kendaraan Bermotor Menurut Jenis, 1949-2017. Tersedia pada: https://www.bps.go.id/linkTableDinamis/ view/id/1133 (Diakses: 31 Agustus
2018).

Baridwan, Z. (2014) Intermediate Accounting. 8 ed. Yogyakarta: BPFE.

Brigham, E. F. dan Houston, J. F. (2019) Fundamentals of Financial Management. 15 ed. Boston: Cengage Learning. doi: 10.2307/2327254.

Direktorat Jenderal Pajak (2018) Penyusutan dan Amortisasi. Tersedia pada: https://www.pajak.go.id/id/penyusutandan-amortisasi (Diakses: 31 Agustus 2018).

Harjito, A. dan Martono (2012) Manajemen Keuangan. 2 ed. Yogyakarta: Ekonisia.

Kahraman, C., Onar, S. Ç. dan Öztayşi, B. (2015) "Present Worth Analysis Using Hesitant Fuzzy Sets," in Proceedings of the 2015 Conference of the International Fuzzy Systems Association and the European Society for Fuzzy Logic and Technology. Gijón: Atlantis Press, hal. 255-259. doi: 10.2991/ifsa-eusflat15.2015.38.

Kasmir dan Jakfar (2007) Studi Kelayakan Bisnis. 2 ed. Jakarta: Kencana.

Situmorang, S. H. dan Dilham, A. (2007) Studi Kelayakan Bisnis Buku II. Medan: USU Press.

Tettamanzi, A. dan Tomassini, M. (2001) Soft Computing Integrating Evolutionary, Neural, and Fuzzy Systems. New York: Springer-Verlag Berlin Heidelberg. doi: 10.1198/tech.2002.s728.

The Engineering Toolbox (2008) Cash Flow Diagrams. Tersedia pada: https://www.engineeringtoolbox.com/cas h-flow-diagrams-d_1231.html (Diakses: 31 Agustus 2018). 